Published in final edited form as:

Ann Epidemiol. 2015 January ; 25(1): 40-45. doi:10.1016/j.annepidem.2014.10.012.

\title{
Preterm birth and long-term maternal cardiovascular health
}

\author{
Wei Perng $^{1}$, Jennifer Stuart ${ }^{2}$, Sheryl L. Rifas-Shiman ${ }^{1}$, Janet W. Rich-Edwards ${ }^{3}$, Alison \\ Stuebe $^{4}$, and Emily Oken ${ }^{1,5}$ \\ ${ }^{1}$ Harvard Medical School and Harvard Pilgrim Health Care Institute, Boston, MA \\ ${ }^{2}$ Department of Epidemiology, Harvard School of Public Health, Boston, MA \\ ${ }^{3}$ Connors Center for Women's Health, Brigham and Women's Hospital, Boston, MA \\ ${ }^{4}$ Obstetrics and Gynecology, University of North Carolina School of Medicine, Chapel Hill, NC \\ ${ }^{5}$ Department of Nutrition, Harvard School of Public Health, Boston, MA
}

\section{Abstract}

Purpose-To investigate whether preterm birth (PTB) is associated with greater cardiovascular disease (CVD) risk in a longitudinal cohort.

\begin{abstract}
Methods-We examined differences in SBP, DBP, insulin resistance (HOMA-IR), total cholesterol, HDL, LDL, triglycerides, CRP, and IL-6 at 3 years postpartum between women who delivered preterm (gestation $<37$ weeks; $n=54$ ) vs. term ( $>37$ weeks; $n=751$ ) using multivariable linear regression. We also assessed relations with BMI, weight change from pre-pregnancy, and waist circumference at 3 and 7 years postpartum.
\end{abstract}

\begin{abstract}
Results-Median age at enrollment was 33.9 years (range: 16.4-44.9). After adjusting for age, race, pre-pregnancy BMI, parity, marital status, education, and SBP during early pregnancy, women with PTB had 3.99 (95\% CI: 0.82, 7.16) $\mathrm{mmHg}$ higher SBP and $7.01(1.54,12.50) \mathrm{mg} / \mathrm{dL}$ lower HDL than those who delivered at term. The association with SBP was attenuated after accounting for hypertension before or during pregnancy $(2.78[-0.30,5.87] \mathrm{mmHg})$. PTB was not related to other postpartum outcomes.
\end{abstract}

Conclusions-PTB is related to greater CVD risk by 3 years postpartum, as indicated by higher SBP and lower HDL. While these associations may be due to preexisting conditions exacerbated during pregnancy, PTB may flag high-risk women for more vigilant CVD monitoring and lifestyle interventions.

(C) 2014 Elsevier Inc. All rights reserved.

Correspondence: Wei Perng, Department of Population Medicine, Harvard Medical School and Harvard Pilgrim Health Care Institute, 133 Brookline Avenue, 3rd Floor, Boston, MA 02215, USA, Phone: (617) 509-9848 Fax: (617) 509-9853, wei.perng@gmail.com, wei_perng@ harvardpilgrim.org.

Publisher's Disclaimer: This is a PDF file of an unedited manuscript that has been accepted for publication. As a service to our customers we are providing this early version of the manuscript. The manuscript will undergo copyediting, typesetting, and review of the resulting proof before it is published in its final citable form. Please note that during the production process errors may be discovered which could affect the content, and all legal disclaimers that apply to the journal pertain. 


\section{Keywords}

preterm birth; cardiovascular disease risk; SBP; HDL; hypertension; reproductive-aged women; longitudinal

\section{INTRODUCTION}

Preterm birth, defined as gestation length $<37$ weeks, occurs in approximately $12.5 \%$ of births in the U.S. each year, affecting roughly 1 in 8 infants (1). Women with a history of preterm delivery are at two- to three-fold greater risk of cardiovascular disease (CVD) (2-7). Yet, the mechanistic pathways are not well understood since most studies investigating this relation have been retrospective analyses of large population registries $(3,4,6)$ or hospitalization records $(2,5,6)$, precluding the ability to explore associations with biomarkers of disease progression.

Although the relations of other pregnancy complications, such as preeclampsia $(5,8-12)$ and gestational diabetes $(10,11,13-15)$, with postpartum cardiometabolic traits are well-studied, we are aware of only two published papers that examined subclinical markers of CVD with respect to preterm birth. In an investigation of mothers in the Avon Longitudinal Study of Parents and Children (ALSPAC), Fraser et al. (10) reported that women who delivered preterm had higher blood pressure 18 years after delivery, but were not different from their counterparts in terms of glycemia, lipids, or adiposity. Additionally, the association with blood pressure was largely explained by hypertension during pregnancy (10). However, in another study of non-hypertensive non-preeclamptic mothers in the Women and Infants Study of Healthy Hearts (WISH) cohort, Catov et al. (16) found that preterm delivery predicted higher blood pressure and an atherogenic lipid profile in the decade following pregnancy. The limited literature points towards the need for additional studies to explore possible etiological mechanisms linking preterm birth to later maternal cardiovascular risk. A better understanding of the biological processes could unveil intervention opportunities and lead to improvements in preventive strategies for both conditions.

In this study, we examined the relation of preterm birth with long-term maternal cardiovascular traits, including blood pressure, glycemia, lipids, and inflammation 3 years after delivery, as well as indicators of overall and central adiposity at 3 and 7 years postpartum in a longitudinal cohort of reproductive-aged women in the Boston area.

\section{METHODS}

\section{Study population}

This study included participants of Project Viva, an ongoing pre-birth cohort of pregnant women and their children enrolled between 1999 and 2002 at a multispecialty clinic in eastern Massachusetts. Details on recruitment and exclusion criteria are reported elsewhere (17). All women provided written informed consent and the Harvard Pilgrim Health Care Institutional Review Board approved this study. 
Since the aim of this investigation was to examine the relation of preterm birth with maternal health at 3 and 7 years postpartum, only participants who did not have an intervening pregnancy between the index birth and the times of outcome assessment were eligible. Of the 2128 mothers who delivered a live singleton, 1534 did not have an intervening pregnancy by the 3 -year visit. We further excluded 769 women without data on any of the 3-year outcomes, and 23 participants missing information on key adjustment covariates (marital status and education), yielding a final analytic sample of 746 women. Of these women, 567 (76\%) provided a blood specimen; 179 were collected in the fasting state (we did not require that women come to the visit fasting). For the 7-year outcomes, there were 1492 women without an intervening pregnancy, 548 of whom we had data on weight or waist circumference at the 7-year assessment. After excluding 18 women with incomplete covariate information, the final sample for the 7-year postpartum analysis comprised 530 mothers; we did not collect blood at 7 years. The 805 women in either the 3- or 7-year postpartum analysis were distinct but overlapping ( $n=471$ in both; $n=59$ in 3-year sample only; $n=275$ in the 7-year sample only), and were similar to those not included $(n=1323)$ in terms of race, ethnicity, marital status, household income, education level, or smoking habits during pregnancy. However, as expected, the women in this study, none of whom had a pregnancy after the index pregnancy, were older (mean age at enrollment 33.2 vs. 31.0 years) and had a higher frequency of multiparity $(69.8 \%$ vs. $41.5 \%)$. The study participants also had higher pre-pregnancy body mass index (BMI; $25.3 \mathrm{vs.} 24.7 \mathrm{~kg} / \mathrm{m}^{2}$ ), and accordingly gained less total weight during pregnancy ( $15.0 \mathrm{vs.} 15.8 \mathrm{~kg})$ than those not included.

\section{Exposure: preterm birth}

We calculated gestational age in weeks by subtracting the date of the last menstrual period from the date of delivery. For subjects whose ultrasound pregnancy dating estimate differed by more than 10 days from the last menstrual period, we used the dating obtained from the $2^{\text {nd }}$ trimester ultrasound to determine gestational age at birth. We categorized infants as preterm if the gestational age at birth was less than 37 completed weeks of gestation.

\section{Outcomes}

Anthropometric assessment-At the in-person 3- and 7-year postpartum visits, research assistants measured the women's weight to the nearest $0.1 \mathrm{~kg}$ using a researchgrade electronic scale, height to the nearest $0.1 \mathrm{~cm}$, and waist circumference to the nearest $0.1 \mathrm{~cm}$ using a Lefkin woven tape. Change in weight was calculated as the difference between weight at 3 or 7 years postpartum and self-reported pre-pregnancy weight. Postpartum BMI was calculated using weight and height (weight $[\mathrm{kg}] /(\text { height }[\mathrm{m}])^{2}$ ).

Laboratory procedures for cardiometabolic biomarkers-At the 3-year visit, trained phlebotomists collected a blood specimen, which was processed within 24 hours and stored at $-80^{\circ} \mathrm{C}$ until time of analysis. We assayed glucose, fasting insulin, total cholesterol, high-density lipoprotein (HDL), low-density lipoprotein (LDL), and triglycerides from the fasting blood samples only $(n=179)$. Glucose was measured enzymatically on a Hitachi 911 analyzer using Roche Diagnostic reagents. Fasting insulin was measured with a microparticle enzyme immunoassay on an IMZ analyzer (Abbott Laboratories). We used these values to determine insulin resistance using the homeostatic model: HOMA-IR= (fasting 
insulin $[\mu \mathrm{U} / \mathrm{mL}] \times$ fasting glucose $[\mathrm{mmol} / \mathrm{L}] / 22.5)$. Total cholesterol was measured enzymatically; LDL was quantified with a homogenous direct method from Genzyme Corp; HDL was assessed using a direct enzymatic colorimetric assay, and triglycerides were determined enzymatically with correction for endogenous glycerol.

Inflammation biomarkers, C-reactive protein (CRP) and interleukin-6 (IL-6), were assayed from all blood specimens ( $n=567)$. We used an immunoturbidimetric high-sensitivity assay on a Hitachi 911 analyzer (Roche Diagnostics) with Denka Seiken reagents and calibrators to quantify CRP concentrations. Plasma IL-6 was measured by ultrasensitive ELISA.

We measured systolic and diastolic blood pressure (SBP and DBP) 5 times, each 1 minute apart, using a Dinamap (Critikon, Inc.) Pro 100 automated oscillometric recorder.

\section{Covariates}

At enrollment, women completed surveys inquiring on sociodemographic information including race/ethnicity (Black/Hispanic/White/Asian/other), education level (primary/ secondary/university) parity (continuous), and partner's height $(\mathrm{cm})$ and weight $(\mathrm{kg})$; and lifestyle characteristics including smoking habits (current/former/never), diet (evaluated as a continuous score representing adherence to various dietary patterns), and physical activity (hours per week). In postpartum questionnaires, mothers provided updates on lifestyle and sociodemographic characteristics and reported on duration of breastfeeding.

We calculated pre-pregnancy BMI $\left(\mathrm{kg} / \mathrm{m}^{2}\right)$ using self-reported pre-pregnancy weight and height. We derived first trimester SBP as the first blood pressure measurement documented in prenatal medical records. The medical records also provided information on perinatal characteristics including prenatal glucose tolerance status (normoglycemic/isolated hyperglycemina/impaired glucose tolerance/gestational diabetes) (18), offspring sex (male/ female), and birthweight (g). We determined birthweight-for-gestational age and sex zscores ('fetal growth') using national reference data (19). Small for gestational age and sex (SGA) was defined as less than $10^{\text {th }}$ percentile and large for gestational age and sex (LGA) as greater than $90^{\text {th }}$ percentile.

To identify women with hypertensive disorders of pregnancy, we reviewed outpatient charts for blood pressure and urine protein results, and created a 4-level variable with the categories normotensive, chronic hypertension, gestational hypertension, and preeclampsia. We categorized women as having chronic hypertension if they were taking antihypertensive medications or if they had two elevated clinically-measured blood pressure values (systolic $>140 \mathrm{mmHg}$ or diastolic $>90 \mathrm{mmHg}$ ) before 20 weeks gestation. We categorized a woman as having gestational hypertension if she did not have chronic hypertension but developed elevated systolic ( $>140 \mathrm{mmHg}$ ) or diastolic ( $>90 \mathrm{mmHg}$ ) blood pressure on two or more occasions after 20 weeks gestation. We classified women as having preeclampsia if they did not have chronic hypertension but developed increased blood pressure as just defined in addition to proteinuria (dipstick value of $1+$ on two or more occasions or $\geq 2$ once) $>4$ hours but $\leq 7$ days or less apart, or if they had chronic hypertension and developed proteinuria after 20 weeks gestation. 


\section{Data analysis}

To identify potential confounders to the relation of preterm birth with the maternal outcomes, we examined the distribution of preterm birth prevalence across categories of sociodemographic, lifestyle, and peripartum characteristics. We evaluated the statistical significance of the associations with the Wald chi-squared statistic for categorical variables, and a test of linear trend for ordinal variables.

Next, we estimated mean differences and 95\% confidence intervals (CI) for maternal cardiovascular risk markers (SBP, DBP, total cholesterol, HDL, LDL, triglycerides, HOMAIR, CRP, and IL-6) at 3 years postpartum for women who had a preterm birth vs. those who delivered at term. For blood pressure, we focused on results for SBP since it is a better predictor of long term outcomes (20) and is more accurately measured than DBP (21). Biomarkers that were not normally distributed (triglycerides, HOMA-IR, CRP, and IL-6) were natural $\log$-(ln)-transformed prior to use in the regression models. In multivariable analyses, we constructed a series of models that first accounted for non-modifiable characteristics (Model 1: maternal age and race/ethnicity), followed by sociodemographic and perinatal factors (Model 2: Model $1+$ pre-pregnancy BMI, parity, marital status and education level), followed by hypertensive disorders of pregnancy (Model 3), which were previously reported to predict postpartum cardiometabolic health (10). Model 2 for blood pressure also included the first clinically-measured SBP during the first trimester, and Model 3 for HOMA-IR also included gestational glucose tolerance, in 4 categories. We used the same set of models to examine associations with the maternal adiposity indicators (BMI, weight change from pre-pregnancy weight, and waist circumference) at 3 and 7 years postpartum. The adjustment covariates were selected based on bivariate associations and our a priori knowledge of CVD risk factors. We also examined associations after accounting for lifestyle characteristics (diet, physical activity, and smoking habits at the postpartum time points) that could influence the maternal outcomes, which resulted in no material difference in the estimates, so these variables were not included in final models.

Excluding 4 mothers who had a planned preterm birth (based on indication of planned Cesarean section ['C-section'], as opposed to an unplanned C-section or vaginal birth) yielded no difference in the results. We also examined the associations with SBP after excluding women with chronic hypertension and those with a pre-pregnancy hypertensive history and observed no substantial differences in the direction, magnitude, or precision of the associations, thus we included all women in the analysis and report these estimates separately in text.

In sensitivity analyses, we further accounted for maternal lifestyle characteristics at each of the postpartum time points, including smoking status, physical activity, and diet. The results were essentially unchanged after inclusion of these variables, so they were not included in the final models.

All analyses were performed with SAS software (v9.3; SAS Institute Inc., Cary, NC). 


\section{RESULTS}

Median age at enrollment was 33.9 years (range: $16.4-44.9$ ); $65.1 \%$ of women were white. Mean \pm SD pre-pregnancy BMI was $25.3 \pm 5.6 \mathrm{~kg} / \mathrm{m}^{2}$. The overall prevalence of preterm birth was $6.7 \%$ ( $n=54)$. In bivariate analysis (Table 1), the frequency of preterm birth differed by race/ethnicity, with the highest prevalence in Asian women, and the lowest in White women. As expected, preterm birth occurrence was higher among women with preeclampsia and chronic hypertension, as well as in single mothers, women with lower education, and those who delivered a small-for-gestational age infant.

The associations of preterm birth with maternal cardiometabolic traits at 3 years postpartum are presented in Table 2 . In our basic model that accounted for age and race/ethnicity (Model 1), women who delivered preterm had 4.93 (95\% CI: 1.51, 8.35) mmHg higher SBP and $7.58(1.95,13.21) \mathrm{mg} / \mathrm{dL}$ lower HDL than their counterparts. Preterm birth also corresponded with $0.37(0.04,0.70)$ units higher ln-transformed HOMA-IR, which translates to $45 \%(4 \%, 101 \%)$ higher HOMA-IR after back-transformation via exponentiation. In Model 2, accounting for pre-pregnancy BMI, parity, marital status, and education somewhat attenuated the association with SBP $(3.81[0.58,7.04] \mathrm{mmHg})$ and $\mathrm{HDL}(-7.01[-12.50$, $-1.54] \mathrm{mg} / \mathrm{dL}$ ), whereas the estimate for HOMA-IR diminished to $2 / 3$ its previous magnitude with the $95 \%$ CI spanning the null $(0.25[-0.05,0.56]$ units ln-transformed HOMA-IR). Adjustment for first trimester SBP and gestation length at the time of assessment did not attenuate the association between preterm birth and SBP (3.99 [0.82, 7.16] mmHg; Table 2 Model 2). Accounting for hypertensive disorders of pregnancy (Model 3) attenuated the estimate for SBP by approximately $30 \%$ to $2.78(-0.30,5.87) \mathrm{mmHg}$, while the estimate for HDL was only slightly attenuated $(-6.67[-12.13,-1.20] \mathrm{mg} / \mathrm{dL})$. For HOMA-IR, adjusting for hypertensive disorders and gestational glucose tolerance individually attenuated the estimate by about $4 \%$ for each; accounting for both conditions in Model 3 led to further attenuation to approximately 3/4 the previous magnitude $(0.20$ $[-0.12,0.51]$ units $\ln$-transformed HOMA-IR). Trends for DBP were similar to those for SBP, but were weaker with wider confidence intervals (Table 2). Preterm birth was not associated with other biomarkers.

Because the relation of preterm birth with postpartum SBP could be explained by preexisting hypertension, we also examined the association after excluding women who reported pre-pregnancy of hypertension or were classified as having chronic hypertension ( $n=13$ both conditions, $n=1$ chronic hypertension only, $n=15$ hypertensive history only). Although the estimates were smaller in magnitude than in the full analysis (Model 1: 4.18 [0.76, 7.60] mmHg; Model 2: 3.27 [0.09, 6.44] mmHg; Model 3: 3.20 [0.13, 6.27] mmHg), the overall trend recapitulated the main results and the $95 \%$ CIs all excluded the null.

Preterm birth was not related to any of the postpartum anthropometric outcomes at either 3 years (Table 2) or 7 years (data not shown). 


\section{DISCUSSION}

Epidemiologic evidence has associated preterm birth with future maternal CVD morbidity and mortality, but few studies have been able to examine potential mechanisms linking these conditions. Using detailed obstetric records and research-quality measures of anthropometry and cardiometabolic traits at 3 and 7 years postpartum in a longitudinal cohort of U.S. women, we found that mothers who delivered a preterm infant had higher SBP (and to a lesser degree, higher DBP) and lower HDL cholesterol by 3 years postpartum, a pattern associated with greater cardiometabolic risk. These relations were robust to adjustment for sociodemographic, perinatal, and lifestyle characteristics, as well as blood pressure during the first trimester.

Researchers have speculated that because premature parturition and CVD share common antecedents, such as inflammation, dyslipidemia, and endothelial dysfunction, its occurrence could unmask later cardiovascular risk $(2,22)$. This hypothesis aligns with a more established literature on preeclampsia, which suggests that placental insufficiency and hypertensive disorders manifest among women who were already at higher risk prior to pregnancy (23). Less is known of these relations with regards to preterm birth, and only two comparable studies have assessed possible mechanistic pathways. Using data from 3,416 ALSPAC mothers, Fraser et al. (10) examined the associations of adverse pregnancy outcomes with a range of cardiovascular risk factors, and found that preterm birth corresponded with higher SBP 18 years after delivery. However, adjusting for hypertensive disorders of pregnancy attenuated the association (10), suggesting that the relation transpired from the influence of hypertension during pregnancy on occurrence of preterm birth, and the subsequent correlation between pregnancy and postpartum blood pressure. In another study of 487 women in the WISH cohort, Catov et al. (16) sought to isolate the 'effect' of preterm birth on postpartum health from that of hypertensive diseases by restricting the study sample to non-preeclamptic women without a history of hypertension. Women with a preterm birth had higher blood pressure, as well as higher total cholesterol, LDL, and triglycerides, 4 to 12 years after pregnancy. The authors also noted that the magnitude of associations was stronger among women with planned as compared to spontaneous preterm births (16). Since planned preterm deliveries are typically indicated in women with medical concerns, this finding suggests the existence of upstream risk factors of both preterm birth and later CVD risk.

In the present study, there were very few cases of indicated preterm deliveries, so we were not able to examine them separately from spontaneous preterm births. We were, however, able to gain insight on etiological pathways underlying the relation of preterm delivery with postpartum SBP by accounting for blood pressure during the first trimester (Model 2) and hypertensive complications that transpired later in pregnancy (Model 3). Counter to our expectations, accounting for first semester SBP did not attenuate the estimate (3.81 [0.58, 7.04] $\mathrm{mmHg}$ vs. 3.99 [CI: 0.82, 7.16] $\mathrm{mmHg}$ before vs. after adjustment for first trimester SBP and gestational age-at-blood-draw). However, in corroboration with findings from Fraser et al. (10), accounting for hypertensive disorders during pregnancy attenuated the estimate towards the null, suggesting that a substantial portion of the relation between preterm birth and higher postpartum SBP is marked by hypertension during mid-to-late 
pregnancy. This could be due to the fact that hypertension is a risk factor for preterm birth that may also cause permanent damage to endothelial vasculature, ultimately leading to long-term alterations in arterial pressure (24). We observed similar trends among women with no history of hypertension and no diagnosis of chronic hypertension during pregnancy (Model 2: $3.27[0.09,6.44] \mathrm{mmHg}$ ), highlighting the importance of monitoring the progression of cardiovascular risk factors among normotensive women with a history of preterm delivery.

We also found an inverse relation of preterm birth with postpartum HDL levels that remained robust to covariate adjustment. While we cannot discount the possibility that this association could be a reflection of adverse lipid profiles prior to or during pregnancy (25, 26), it is a salient finding considering that low HDL is a strong predictor of CVD risk (2729), irrespective of other lipid components (28). Interestingly, in the WISH study, preterm birth predicted alterations in total cholesterol, LDL, and triglycerides, but not HDL. The discrepancy could be due to differences in population composition, and thus different predisposing factors for preterm birth as well as CVD. Additionally, the participants in WISH exhibited a worse cardiovascular risk profile than women in the present study, and it is possible that reductions in HDL precede elevations in the other lipid components. Future studies examining associations of preterm birth with lipid fractions over a longer duration of follow-up are warranted in other populations.

In addition to our main findings, there were two other noteworthy trends. First, we observed a direct association between preterm birth and insulin resistance at 3 years postpartum after accounting for age and race/ethnicity. Although the association became attenuated after covariate adjustment, this may have been an artifact of the small sample size of women who provided fasting blood. Because insulin resistance is part of the cluster of inflammationmediated metabolic perturbations that could transpire through endothelial dysfunction (30), future studies should assess this association in a larger population of women. It is also worth mentioning that preterm birth did not predict BMI, weight change, or waist circumference by 3 or 7 years postpartum, indicating that the associations with metabolic sequelae were not mediated by changes in maternal adiposity.

This study has some limitations. First, there is the possibility of selection bias since we restricted the analysis to women without intervening pregnancies, who may be inherently different from their counterparts; thus limiting generalizability. Second, there could be selfreport bias of pre-pregnancy weight. However, we conducted a validation study comparing self-reported pre-pregnancy weight with clinically-measured weight in the medical records within 3 months before the last menstrual period; correlation between self-reported and objectively-measured BMI was high $(r=0.99)$, and mean underreporting of weight $(\sim 1 \mathrm{~kg})$ did not differ by race/ethnicity, gestational age at study enrollment, or weight itself (31); thus, the degree of self-report bias likely had minimal effect on the results. Third, due to the small number of preterm births and because we did not require fasting biospecimens, we may have been underpowered to detect smaller associations for some of the biomarkers. We hope to improve participation in blood draws for future studies and request that women fast prior to the visit. Third, we did not have data on use of statins or anti-hypertensive medications, which could influence some of the postpartum outcomes, although excluding 
women with a history of diagnosed hypertension did not alter findings. Fourth, because Project Viva participants are predominantly white, relatively well-educated, and all resided in one region of the U.S., the results may not be generalizable to other populations. Finally, we cannot discount the possibility of chance findings.

In conclusion, delivery of a preterm infant was associated with higher SBP and lower HDL at 3 years postpartum. Although the magnitudes of associations are modest, they are comparable to subclinical differences detected in young adults (32) and may have important implications for longer term cardiovascular risk. For example, considering that a10 $\mathrm{mmHg}$ increment in SBP was associated with 1.5 to 2.5 times greater risk of CVD over 10 years of follow-up among middle-aged women in the Framingham cohort (33), the $\sim 4 \mathrm{mmHg}$ difference we observed between women with vs. without a preterm birth may have implications for long term cardiovascular health. Our findings suggest that excess CVD risk is detectable among reproductive-aged women with a history of preterm birth before establishment of overt clinical disease. Possible avenues for CVD prevention include more frequent lipid and blood pressure screening, and earlier behavioral interventions (e.g. diet and lifestyle modifications) (34), both of which have been previously shown to improve CVD risk parameters (34).

\section{Acknowledgments}

This work was funded by NIH grants R21 DK053539, R37 HD 034567, R01 HL 064925, and R01 HL 075504. Dr. Oken was supported by K24 HD069408, P30 DK092924. Dr. Perng was supported by the Thomas O'Pyle fellowship at the Harvard Pilgrim Health Care Institute.

We are indebted to the mothers and children of Project Viva for their generous participation, and appreciate the invaluable assistance of past and present Project Viva staff.

\section{Abbreviations}

$\begin{array}{ll}\text { BMI } & \text { body mass index } \\ \text { GWG } & \text { gestational weight gain } \\ \text { CRP } & \text { C-reactive protein } \\ \text { DBP } & \text { diastolic blood pressure } \\ \text { IL-6 } & \text { interleukin-6 } \\ \text { HDL } & \text { high density lipoprotein } \\ \text { LDL } & \text { low density lipoprotein } \\ \text { SBP } & \text { systolic blood pressure }\end{array}$

\section{References}

1. Center for Disease Control and Prevention. Preterm Birth. [cited 2014 February 19]. Available from: http://www.cdc.gov/reproductivehealth/maternalinfanthealth/PretermBirth.htm.

2. Hastie CE, Smith GC, Mackay DF, Pell JP. Maternal risk of ischaemic heart disease following elective and spontaneous pre-term delivery: retrospective cohort study of 750350 singleton pregnancies. Int J Epidemiol. 2011; 40(4):914-9. [PubMed: 21278195] 
3. Pell JP, Smith GC, Walsh D. Pregnancy complications and subsequent maternal cerebrovascular events: a retrospective cohort study of 119,668 births. Am J Epidemiol. 2004; 159(4):336-42. [PubMed: 14769636]

4. Smith GC, Pell JP, Walsh D. Pregnancy complications and maternal risk of ischaemic heart disease: a retrospective cohort study of 129,290 births. Lancet. 2001; 357(9273):2002-6. [PubMed: 11438131]

5. Catov JM, Wu CS, Olsen J, Sutton-Tyrrell K, Li J, Nohr EA. Early or recurrent preterm birth and maternal cardiovascular disease risk. Ann Epidemiol. 2010; 20(8):604-9. [PubMed: 20609340]

6. Kessous R, Shoham-Vardi I, Pariente G, Holcberg G, Sheiner E. An association between preterm delivery and long-term maternal cardiovascular morbidity. Am J Obstet Gynecol. 2013; 209(4):368, e1-8. [PubMed: 23800639]

7. Bonamy AK, Parikh NI, Cnattingius S, Ludvigsson JF, Ingelsson E. Birth characteristics and subsequent risks of maternal cardiovascular disease: effects of gestational age and fetal growth. Circulation. 2011; 124(25):2839-46. [PubMed: 22124377]

8. Irgens HU, Reisaeter L, Irgens LM, Lie RT. Long term mortality of mothers and fathers after preeclampsia: population based cohort study. BMJ. 2001; 323(7323):1213-7. [PubMed: 11719411]

9. Skjaerven R, Wilcox AJ, Klungsoyr K, Irgens LM, Vikse BE, Vatten LJ, et al. Cardiovascular mortality after pre-eclampsia in one child mothers: prospective, population based cohort study. BMJ. 2012; 345:e7677. [PubMed: 23186909]

10. Fraser A, Nelson SM, Macdonald-Wallis C, Cherry L, Butler E, Sattar N, et al. Associations of pregnancy complications with calculated cardiovascular disease risk and cardiovascular risk factors in middle age: the Avon Longitudinal Study of Parents and Children. Circulation. 2012; 125(11):1367-80. [PubMed: 22344039]

11. Mangos GJ, Spaan JJ, Pirabhahar S, Brown MA. Markers of cardiovascular disease risk after hypertension in pregnancy. J Hypertens. 2012; 30(2):351-8. [PubMed: 22179081]

12. Magnussen EB, Vatten LJ, Smith GD, Romundstad PR. Hypertensive disorders in pregnancy and subsequently measured cardiovascular risk factors. Obstet Gynecol. 2009; 114(5):961-70. [PubMed: 20168095]

13. Catalano PM, Kirwan JP, Haugel-de Mouzon S, King J. Gestational diabetes and insulin resistance: role in short- and long-term implications for mother and fetus. J Nutr. 2003; 133(5 Suppl 2):1674s-83s. [PubMed: 12730484]

14. Stuebe AM, Mantzoros C, Kleinman K, Gillman MW, Rifas-Shiman S, Seely EW, et al. Gestational glucose tolerance and maternal metabolic profile at 3 years postpartum. Obstet Gynecol. 2011; 118(5):1065-73. [PubMed: 22015874]

15. Vrachnis N, Augoulea A, Iliodromiti Z, Lambrinoudaki I, Sifakis S, Creatsas G. Previous gestational diabetes mellitus and markers of cardiovascular risk. Int J Endocrinol. 2012; 2012:458610. [PubMed: 22518122]

16. Catov JM, Dodge R, Barinas-Mitchell E, Sutton-Tyrrell K, Yamal JM, Piller LB, et al. Prior preterm birth and maternal subclinical cardiovascular disease 4 to 12 years after pregnancy. $\mathrm{J}$ Womens Health. 2013; 22(10):835-43.

17. Oken E, Baccarelli A, Gold D, Kleinman K, Litonjua A, De Meo E. Cohort profile: Project Viva. Int J Epidemiol. In Press.

18. Regnault N, Gillman MW, Rifas-Shiman SL, Eggleston E, Oken E. Sex-specific associations of gestational glucose tolerance with childhood body composition. Diabetes Care. 2013; 36(10): 3045-53. [PubMed: 23877978]

19. Oken E, Kleinman KP, Rich-Edwards J, Gillman MW. A nearly continuous measure of birth weight for gestational age using a United States national reference. BMC Pediatr. 2003; 3:6. [PubMed: 12848901]

20. Miura K, Daviglus ML, Dyer AR, Liu K, Garside DB, Stamler J, et al. Relationship of blood pressure to 25-year mortality due to coronary heart disease, cardiovascular diseases, and all causes in young adult men: the Chicago Heart Association Detection Project in Industry. Arch Intern Med. 2001; 161(12):1501-8. [PubMed: 11427097]

Ann Epidemiol. Author manuscript; available in PMC 2016 January 01. 
21. Heinemann M, Sellick K, Rickard C, Reynolds P, McGrail M. Automated versus manual blood pressure measurement: a randomized crossover trial. Int J Nurs Pract. 2008; 14(4):296-302. [PubMed: 18715391]

22. Sattar N. Do pregnancy complications and CVD share common antecedents? Atheroscler Suppl. 2004; 5(2):3-7. [PubMed: 15121029]

23. Romundstad PR, Magnussen EB, Smith GD, Vatten LJ. Hypertension in pregnancy and later cardiovascular risk: common antecedents? Circulation. 2010; 122(6):579-84. [PubMed: 20660802]

24. Gilbert JS, Ryan MJ, LaMarca BB, Sedeek M, Murphy SR, Granger JP. Pathophysiology of hypertension during preeclampsia: linking placental ischemia with endothelial dysfunction. Am J Physiol. 2008; 294(2):H541-50.

25. Catov JM, Bodnar LM, Kip KE, Hubel C, Ness RB, Harger G, et al. Early pregnancy lipid concentrations and spontaneous preterm birth. Am J Obstet Gynecol. 2007; 197(6):610, e1-7. [PubMed: 18060950]

26. Catov JM, Ness RB, Wellons MF, Jacobs DR, Roberts JM, Gunderson EP. Prepregnancy lipids related to preterm birth risk: the coronary artery risk development in young adults study. J Clin Endocrinol Metab. 2010; 95(8):3711-8. [PubMed: 20501685]

27. Di Angelantonio E, Sarwar N, Perry P, Kaptoge S, Ray KK, Thompson A, et al. Major lipids, apolipoproteins, and risk of vascular disease. JAMA. 2009; 302(18):1993-2000. [PubMed: 19903920]

28. Gordon T, Castelli WP, Hjortland MC, Kannel WB, Dawber TR. High density lipoprotein as a protective factor against coronary heart disease. The Framingham Study. Am J Med. 1977; 62(5): 707-14. [PubMed: 193398]

29. Wilson PW, Abbott RD, Castelli WP. High density lipoprotein cholesterol and mortality. The Framingham Heart Study. Arteriosclerosis. 1988; 8(6):737-41. [PubMed: 3196218]

30. Hsueh WA, Quinones MJ. Role of endothelial dysfunction in insulin resistance. Am J Cardiol. 2003; 92(4a):10j-7j.

31. Oken E, Taveras EM, Kleinman KP, Rich-Edwards JW, Gillman MW. Gestational weight gain and child adiposity at age 3 years. Am J Obstet Gynecol. 2007; 196(4):322. e1-8. [PubMed: 17403405]

32. Kestila P, Magnussen CG, Viikari JS, Kahonen M, Hutri-Kahonen N, Taittonen L, et al. Socioeconomic status, cardiovascular risk factors, and subclinical atherosclerosis in young adults: the cardiovascular risk in Young Finns Study. Arterioscler Thromb Vasc Biol. 2012; 32(3):81521. [PubMed: 22223734]

33. Kannel WB, Vasan RS, Levy D. Is the relation of systolic blood pressure to risk of cardiovascular disease continuous and graded, or are there critical values? Hypertension. 2003; 42(4):453-6. [PubMed: 12975387]

34. Robbins CL, Dietz PM, Bombard J, Tregear M, Schmidt SM, Tregear SJ. Lifestyle interventions for hypertension and dyslipidemia among women of reproductive age. Prev Chron Dis. 2011; 8(6):A123. 


\section{Table 1}

Occurrence of preterm birth (gestational age <37 vs. $\geq 37$ weeks)

\begin{tabular}{|c|c|c|c|}
\hline & & Pretern & birth \\
\hline & $\mathrm{N}^{a}$ & $\%(n)$ & $P^{b}$ \\
\hline Overall & 805 & $6.7(54)$ & \\
\hline \multicolumn{4}{|c|}{ Maternal \& family characteristics } \\
\hline Age at enrollment & & & 0.50 \\
\hline $15-24$ years & 65 & $6.2(4)$ & \\
\hline $25-34$ years & 407 & $7.6(31)$ & \\
\hline $35-44$ years & 333 & $5.7(19)$ & \\
\hline Race/ethnicity & & & 0.001 \\
\hline Black & 141 & $7.8(11)$ & \\
\hline Hispanic & 64 & $14.1(9)$ & \\
\hline White & 523 & $4.6(24)$ & \\
\hline Asian & 40 & $20.0(8)$ & \\
\hline Other & 35 & $5.7(2)$ & \\
\hline Marital status & & & 0.07 \\
\hline Married/cohabiting & 728 & $6.2(45)$ & \\
\hline Single & 77 & $11.7(9)$ & \\
\hline Annual household income & & & 0.66 \\
\hline$<\$ 20,000$ & 33 & $6.1(2)$ & \\
\hline$\$ 20,000-\$ 39,999$ & 96 & $7.3(7)$ & \\
\hline$\$ 40,000-\$ 69,999$ & 171 & $4.1(7)$ & \\
\hline$>\$ 70,000$ & 434 & $7.1(31)$ & \\
\hline Education & & & 0.01 \\
\hline Primary & 76 & $10.5(8)$ & \\
\hline Secondary & 484 & $7.9(38)$ & \\
\hline University & 245 & $3.3(8)$ & \\
\hline Smoking habits & & & 0.45 \\
\hline Never & 560 & $7.3(41)$ & \\
\hline Quit before pregnancy & 157 & $4.5(7)$ & \\
\hline Smoked in early pregnancy & 86 & $7.0(6)$ & \\
\hline Partner's BMI & & & 0.76 \\
\hline Not overweight $\left(<25 \mathrm{~kg} / \mathrm{m}^{2}\right)$ & 273 & $7.0(19)$ & \\
\hline Overweight ( $225 \mathrm{~kg} / \mathrm{m}^{2}$ ) & 500 & $6.4(32)$ & \\
\hline \multicolumn{4}{|l|}{ Perinatal characteristics } \\
\hline Parity & & & 0.67 \\
\hline 0 & 243 & $7.4(18)$ & \\
\hline 1 & 360 & $6.4(23)$ & \\
\hline$\geq 2$ & 202 & $6.4(13)$ & \\
\hline Pre-pregnancy BMI & & & 0.40 \\
\hline
\end{tabular}




\begin{tabular}{|c|c|c|c|}
\hline & & Preterm & birth \\
\hline & $\mathrm{N}^{a}$ & $\%(n)$ & $p^{b}$ \\
\hline Underweight $\left(<18.5 \mathrm{~kg} / \mathrm{m}^{2}\right)$ & 27 & $0.0(0)$ & \\
\hline Normal $\left(18.5-24.9 \mathrm{~kg} / \mathrm{m}^{2}\right)$ & 415 & $6.5(29)$ & \\
\hline Overweight $\left(25.0-29.9 \mathrm{~kg} / \mathrm{m}^{2}\right)$ & 177 & $7.8(15)$ & \\
\hline Obese ( $\geq 30.0 \mathrm{~kg} / \mathrm{m}^{2}$ ) & 432 & $7.0(10)$ & \\
\hline Pre-pregnancy hypertensive history & & & 0.80 \\
\hline Yes & 39 & $7.7(3)$ & \\
\hline No & 707 & $6.7(47)$ & \\
\hline Gestational glucose tolerance & & & 0.23 \\
\hline Normoglycemic & 654 & $6.0(39)$ & \\
\hline Isolated hyperglycemia & 79 & $5.1(4)$ & \\
\hline Impaired glucose tolerance & 31 & $9.7(3)$ & \\
\hline Gestational diabetes & 37 & $10.8(4)$ & \\
\hline Hypertensive disorders of pregnancy & & & 0.001 \\
\hline Normal & 721 & $5.7(41)$ & \\
\hline Chronic hypertension & 15 & $20.0(3)$ & \\
\hline Gestational hypertension & 45 & $8.9(4)$ & \\
\hline Preeclampsia & 24 & $25.0(6)$ & \\
\hline Mode of delivery & & & 0.06 \\
\hline Vaginal & 621 & $5.8(36)$ & \\
\hline $\mathrm{C}$-section & 183 & $9.8(18)$ & \\
\hline Childs sex & & & 0.11 \\
\hline Male & 407 & $8.1(33)$ & \\
\hline Female & 398 & $5.3(21)$ & \\
\hline Fetal growth & & & 0.002 \\
\hline SGA (<10th \%ile) & 40 & $15.0(6)$ & \\
\hline AGA $(10-\unlhd 90$ th $\%$ ile $)$ & 643 & $7.2(46)$ & \\
\hline LGA (>90th \%ile) & 121 & $1.7(2)$ & \\
\hline Prudent dietary pattern during $1^{\text {st }}$ trimester & & & 0.19 \\
\hline Q1 (least similar) & 181 & $8.8(16)$ & \\
\hline Q2 & 182 & $6.6(12)$ & \\
\hline Q3 & 181 & $7.2(13)$ & \\
\hline Q4 (most similar) & 182 & $5.0(9)$ & \\
\hline Western dietary pattern during $1^{\text {st }}$ trimester & & & 0.51 \\
\hline Q1 (least similar) & 182 & $8.8(16)$ & \\
\hline Q2 & 181 & $6.1(11)$ & \\
\hline Q3 & 181 & $5.5(10)$ & \\
\hline Q4 (most similar) & 182 & $7.1(13)$ & \\
\hline Pre-pregnancy physical activity & & & 0.32 \\
\hline Q1 (lowest) & 151 & $12.6(19)$ & \\
\hline Q2 & 149 & $2.0(3)$ & \\
\hline Q3 & 204 & $5.9(12)$ & \\
\hline
\end{tabular}




\begin{tabular}{cccc}
\hline & \multicolumn{3}{c}{ Preterm birth } \\
& $\mathbf{N}^{a}$ & $\%(n)$ & $\boldsymbol{P}^{b}$ \\
Q4 (highest) & 173 & $8.1(14)$ & \\
\hline
\end{tabular}

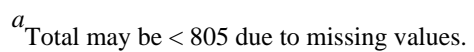

${ }^{b}$ Represents a test for linear trend in which the ordinal predictor is entered into the model as a continuous variable, except for race/ethnicity, smoking habits, partner's BMI, pre-pregnancy hypertensive history, hypertensive disorders of pregnancy, and delivery method (Wald test). 


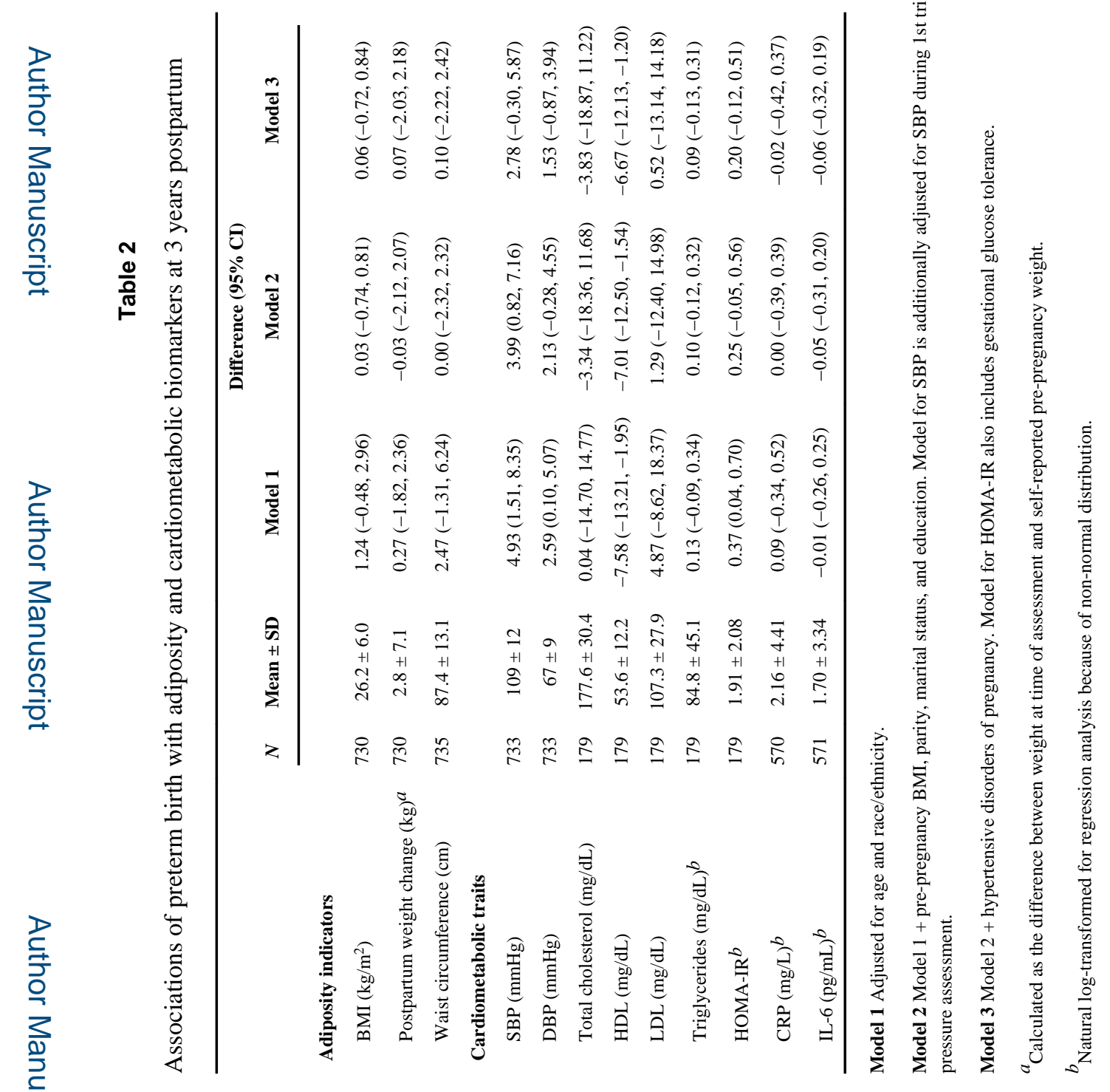

Ann Epidemiol. Author manuscript; available in PMC 2016 January 01. 